\title{
A Novel Line Current Control Strategy to Control the Real Power Flow at PCC Using H-bridge Inverter
}

\author{
Qusay Salem ${ }^{1}$, Jian Xie ${ }^{2}$ \\ Institute of Energy Conversion and Storage, University of Ulm, Germany
}

\begin{tabular}{l}
\hline \hline Article Info \\
\hline Article history: \\
Received Jan 17, 2018 \\
Revised Feb 22, 2018 \\
Accepted Apr 3, 2018 \\
\hline Keyword: \\
H-bridge inverter \\
Line current control strategy \\
P/V droop control \\
Microgrid \\
Distribution network
\end{tabular}

\begin{abstract}
This paper presents the power flow control between the main grid and the microgrid in low-voltage distribution network using H-bridge inverter. Controlling the real power flow in the line using the $\mathrm{H}$-bridge inverter is investigated by implementing the line current control strategy. The feasibility of the proposed H-bridge inverter and its control strategy is validated by varying the line current reference. Hence, the H-bridge inverter will operate in its inductive or capacitive operation mode depending on the reference current value and the output of the PI controller in the control unit. The control strategy of the microgrid distributed generators has also been investigated in which $\mathrm{P} / \mathrm{V}$ droop characteristics is applied to the power control of each DG in the microgrid. The effectiveness of the proposed approaches is validated through simulations.
\end{abstract}

Copyright $\odot 2018$ Institute of Advanced Engineering and Science. All rights reserved.

\section{Corresponding Author:}

Qusay Salem,

Institute of Energy Conversion and Storage,

University of Ulm,

Albert-Einstein-Allee 47, 89081, Ulm, Germany.

Email: qusay.salem@uni-ulm.de

\section{INTRODUCTION}

Centralized control methods have been widely applied to control the power and voltage at PCC [1]. However, technical challenges are expected to be encountered by using the centralized schemes. A complex communication network is needed to collect the whole data and the central coordinator has to process all the information without any failure. Otherwise, the whole system will fail [2]. With the rapid development of the distributed generators penetration into the distribution network, controlling the power exchange based on decentralized manner through PCC between the utility grid and a microgrid is needed [3-4]. Therefore, in this paper, this power exchange is controlled by means of transformerless H-bridge inverter. Controlling the power flow at PCC has been done in the transmission or distribution network by using series compensators. Those compensators are mostly based on multilevel or cascaded H-bridge inverters [5-8]. So that, in this work, the power flow between the utility or main grid and the microgrid has been investigated by installing a non-cascaded H-bridge inverter at PCC. The power flow control between both networks can be achieved by controlling either the real power at PCC, the inverter reactive power, or the line current. A few researches have been conducted on the line current control between the two networks [9-10]. Hence, the real power control in this research has been done by controlling the line current at PCC. The distributed control of microgrids are mostly dependent on the conventional frequency droop for active power and voltage droop for reactive power [11-14]. However, in low voltage distribution network, the lines are usually resistive with high ratio of $R / X$. Hence, the microgrid power control in this work is dependent on $P / V$ droop control between the active power and the RMS voltage of every DG unit.

In summary, the PCC power flow controller is considered as transformerless H-bridge inverter connected between the main grid and microgrid. The line current control strategy is described and proposed 
to be applied on the H-bridge inverter control unit. The microgrid operation and control with the $P / V$ droop control method has also been described. Two cases have been considered, the first case is when the total real power at PCC is greater than the utility load demand and the second case is when the utility load demand is greater than the total generated real power.

\section{LINE CURRENT CONTROL STRATEGY}

In this control strategy, the reference value of achieving the power flow will be a reference current specified by the grid or system operator rather than injecting reference real or reactive power into the line. It's worth noting that the magnitude of the reference current provided by the grid operator would only control the H-bridge inverter operation either capacitive or inductive. In other words, the value of the line current magnitude will not follow or be the same as the reference current value. The reference current is responsible only of injecting either capacitive or inductive series voltage into the line by varying the modulation index. The H-bridge control is synchronized with the line current by using a phase locked loop. Besides, the injected voltage through the line is $\left( \pm 90^{\circ}\right)$ phase shifted depending on the PI controller output either positive or negative.

The line current magnitude is compared with the reference current assigned by the grid operator and using PI controller, the reference quadrature voltage is generated. Moreover, by dividing the measured DC link voltage over the reference quadrature voltage, then the modulation index of the injected quadrature voltage $\left(u_{q, \max }\right)$ is assigned. The reference value of the DC link voltage is compared with the measured value of the capacitor voltage, and then the error is passed through PI controller so that the in-phase part of the injected voltage $\left(u_{d, \max }\right)$ is generated. To maintain the voltage amplitude of the in-phase injected voltage within its appropriate range, a limiter with boundaries $\left( \pm u_{d, \max }\right)$ is applied. The overall control strategy is shown in Figure 1.

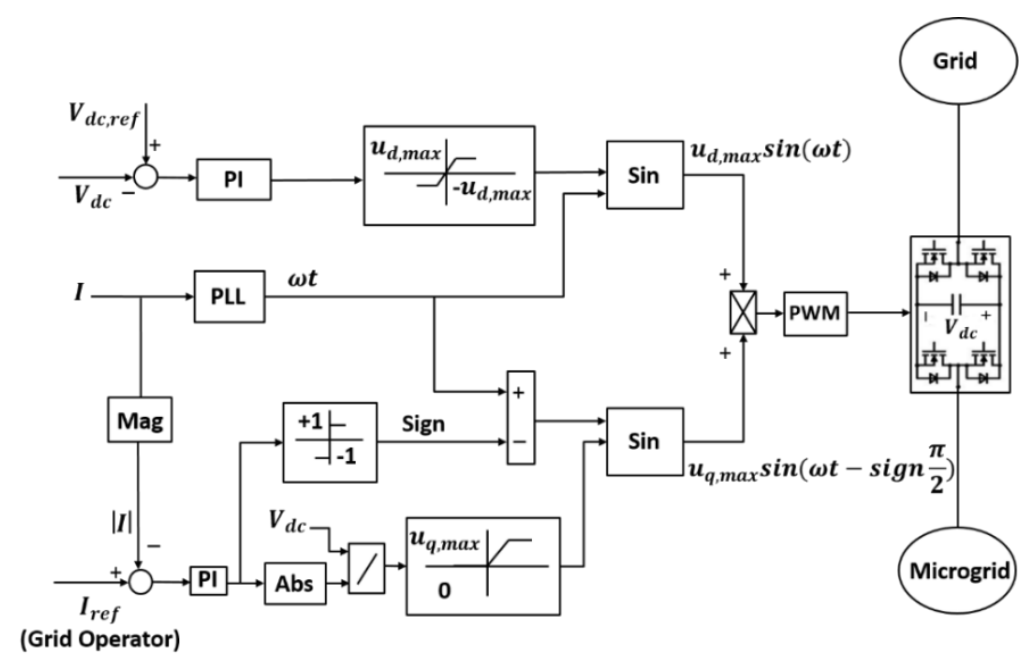

Figure 1. Line current control strategy

\section{DG CONTROL STRATEGY}

In single phase power systems, generating the secondary orthogonal phase is quite challenging. A second order generalized integrator (SOGI) is applied to obtain the fictitious phase so as to form a virtual two-phase system in which $\omega$ is the fundamental angular frequency, and $k$ is the damping factor. According to the selected damping factor, the performance can be improved under distorted grid voltages in addition to the filtering feature that can be obtained [15]. From Figure 2 (a), the characteristic transfer function of the SOGI is stated as:

$$
\frac{V_{D G, \alpha}(s)}{V_{D G}(s)}=\frac{k \omega s}{s^{2}+k \omega s+\omega^{2}}
$$


$\frac{V_{D G, \beta}(s)}{V_{D G}(s)}=\frac{k \omega^{2}}{s^{2}+k \omega s+\omega^{2}}$

Then the following orthogonal two-phase system is obtained without considering the harmonic content of the current and voltage:

$V_{\alpha}=V_{i} \sin (\omega t)$

$V_{\beta}=-V_{i} \cos (\omega t)$

$i_{\alpha}=i_{i} \sin (\omega t-\Phi)$

$i_{\beta}=-i_{i} \cos (\omega t-\Phi)$

In low voltage distribution network, the voltage depends mainly on the real power. So that, the following equation is applied for every DG control strategy:

$P=-k_{p}\left(u-u_{0}\right)+P_{0}$

Where, $P$ is reference real power, $P_{0}$ is the initial real power, $k_{p}$ is the droop gain, $u$ is the measured rms voltage of every $\mathrm{DG}, u_{0}$ is the initial rms voltage.

Figure 2 (b) depict the power control and current control loops of every DG unit. In the power control loop, the $\mathrm{P} / \mathrm{V}$ droop control is applied to generate the reference real power of every DG while the reactive power is assigned as fixed value. In the current control loop, the reference dq current components are compared with the measured dq current components and by using PI controllers, the reference dq voltage components of the DG voltage is generated. Finally, the sinwave signal of the DG voltage is established by inverse dq transformation.

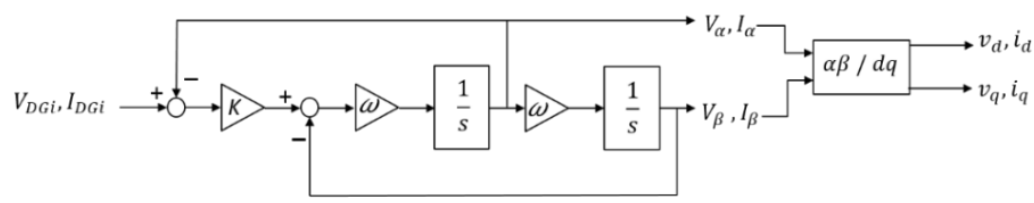

(a)

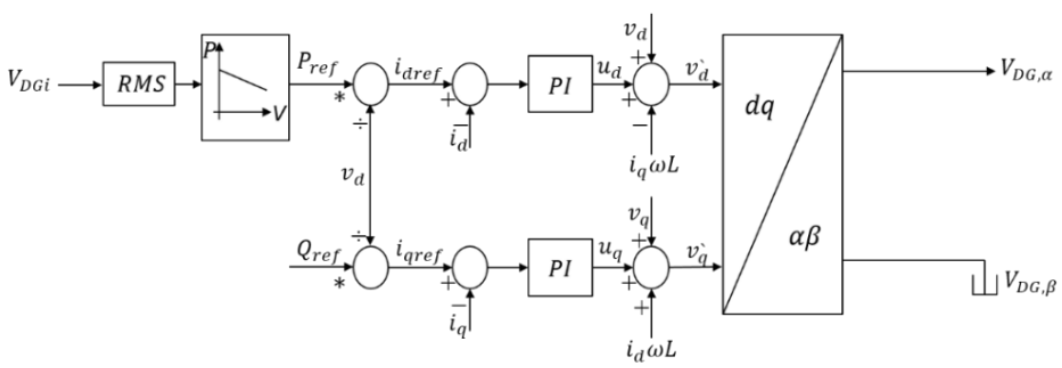

(b)

Figure 2. Distributed generator control strategy

\section{SIMULATION RESULTS}

The simulation model of the proposed network is depicted in Figure 3. The microgrid consists of 10 distributed generators and the transformerless H-bridge inverter is located at PCC to control the real power flow. Every DG is modelled as a controlled voltage source which is controlled by $P / V$ droop characteristic and the utility load is assumed to be resistive. The simulation parameters are all given in Table 1 . The lines connecting the DGs to PCC are assumed to be more resistive and each line has $(100 \mathrm{~m})$ length. The 
performance of the proposed $\mathrm{H}$-bridge inverter is validated in both inductive and capacitive operation modes using the line current control strategy.

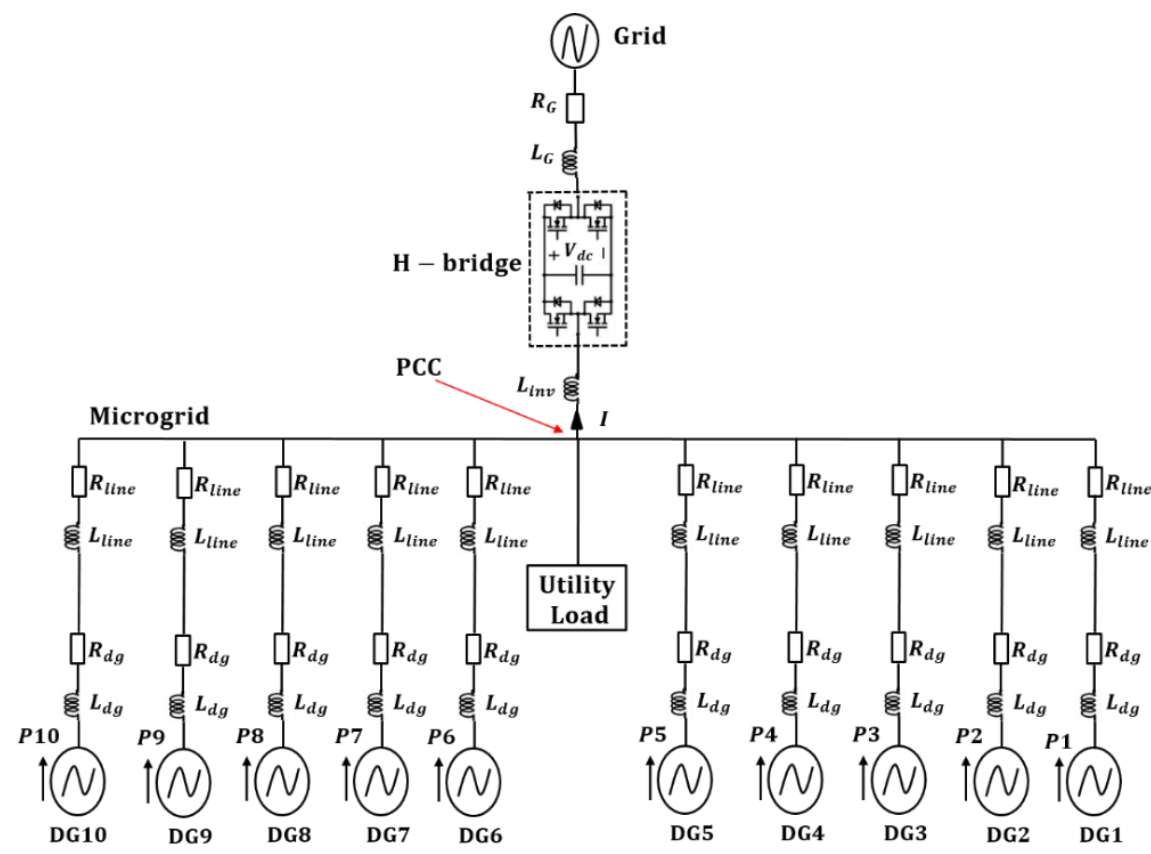

Figure 3. Simulation model of the proposed network

Table 1 Simulation network parameters

\begin{tabular}{|c|c|c|c|c|}
\hline Grid & Lines & H-bridge inverter & Utility Load & Microgrid DG \\
\hline$V_{r m s}: 230 \mathrm{~V}$ & $\begin{array}{l}R_{\text {Line }}: \\
0.8^{*} 0.1 \Omega\end{array}$ & $V_{\text {dcref }}: 20 \mathrm{~V}$ & $\begin{array}{l}P_{L}: 73 \mathrm{~kW} \text { in } \\
\text { case } 1 .\end{array}$ & $\begin{array}{l}R_{D G i}: 1 \mathrm{~m} \Omega \\
L_{D G i}: 0.1 \mathrm{mH}\end{array}$ \\
\hline & & $\mathrm{C}: 0.01 \mathrm{~F}$ & & $P_{0}: 9 \mathrm{~kW}$ \\
\hline$R_{g}: 2.5 \mathrm{~m} \Omega$ & $\begin{array}{l}L_{\text {Line }}: \\
0.26 * 0.1 \mathrm{mH}\end{array}$ & $\begin{array}{l}\mathrm{f}_{\mathrm{S}}: 10 k H z \\
\mathrm{~L}_{\text {inv }}: 100 \mu H\end{array}$ & $\begin{array}{l}P_{L}: 113 \mathrm{~kW} \\
\text { in case } 2 .\end{array}$ & $Q_{0}: 2 k V A R$ \\
\hline$L_{g}: 0.1 \mathrm{mH}$ & & $\begin{array}{ll}\mathrm{K}_{\mathrm{Pi}}, \mathrm{K}_{\mathrm{Ii}}: 0.4,1 \mathrm{e}^{-6} \\
\mathrm{~K}_{\mathrm{P}, \mathrm{dc}}, \mathrm{K}_{\mathrm{I}, \mathrm{dc}}: 0.04,0.5\end{array}$ & & $\begin{array}{l}\mathrm{P}\left(K_{P}, K_{I}\right): \\
15,1 e^{-6} \\
\mathrm{Q}\left(K_{P}, K_{I}\right): \\
20,1 e^{-6}\end{array}$ \\
\hline
\end{tabular}

\subsection{Case 1: $P_{P C C}>0$}

In this case, the $\mathrm{H}$-bridge inverter behaves as an inductive impedance to reduce the real power export at PCC from the microgrid to the main grid depending on the controlled line current value. Before $(\mathrm{t}<$ $1 \mathrm{~s})$, the H-bridge control unit is blocked and consequently, the injected voltage is disabled. After $(\mathrm{t}>1 \mathrm{~s})$, the H-bridge control unit starts to operate and the injected voltage is enabled, respectively. The line current is controlled from 175 A to $140 \mathrm{~A}$ as depicted in Figure 4 (a). Figure 4 (b) depict the real and reactive power of the H-bridge inverter. The real power value is zero during the inductive operation mode since the angle is $\left(+90^{\circ}\right)$ with respect to the line current. The reactive power generated from the H-bridge inverter is a result of injecting series inductive voltage. The DC link voltage is regulated to its reference value $(20 \mathrm{~V})$ as depicted in Figure 4 (c). Figure 4 (d) demonstrates the injected peak to peak voltage which appears at the terminals of the H-bridge. It is clearly shown that the injected voltage is zero before ( $\mathrm{t}<1 \mathrm{~s})$ since the control unit is disabled, whereas after $(t>1 \mathrm{~s})$, the injected voltage is appeared as $20 \mathrm{~V}$ peak to peak. Figure 4 (e)-(f) depict the H-bridge voltage magnitude and phase angle with respect to the line current. As demonstrated, the injected voltage magnitude of the $\mathrm{H}$-bridge is oscillating near the dc link voltage reference. Also, the phase angle is $+90^{\circ}$ with respect to the line current. 
Figure 5 (a) show the RMS voltage (orange line) and real power (blue line) at PCC before and after the H-bridge operation. The RMS voltage at PCC is increased as a result of injecting inductive voltage into the line and the real power at PCC is controlled from $(20 \mathrm{~kW})$ to zero as a consequence of the balance between the total generated power and the utility load demand. The RMS voltage and real power of every distributed generator are depicted in Figure $5(\mathrm{~b})$. After $(\mathrm{t}>1 \mathrm{~s})$, it is clearly shown that the RMS voltage of the DG is increased to a value which satisfy the PCC voltage increase. Also, the real power of every DG is decreased at ( $\mathrm{t}>1 \mathrm{~s}$ ) from $9.3 \mathrm{~kW}$ to $8.2 \mathrm{~kW}$ as their RMS voltages are increased. This variation of the DGs real power is due to the $P / V$ droop characteristic between the generated real power and the RMS voltage of every DG unit. Moreover, because of the resistive nature of the network and as the real power of the utility load is proportional to the PCC voltage, the real power of the load is increased from $73 \mathrm{~kW}$ to $82 \mathrm{~kW}$ as shown in Figure 5 (c). Figure 5 (d) depict the injected voltage and the line current in the inductive operation mode.
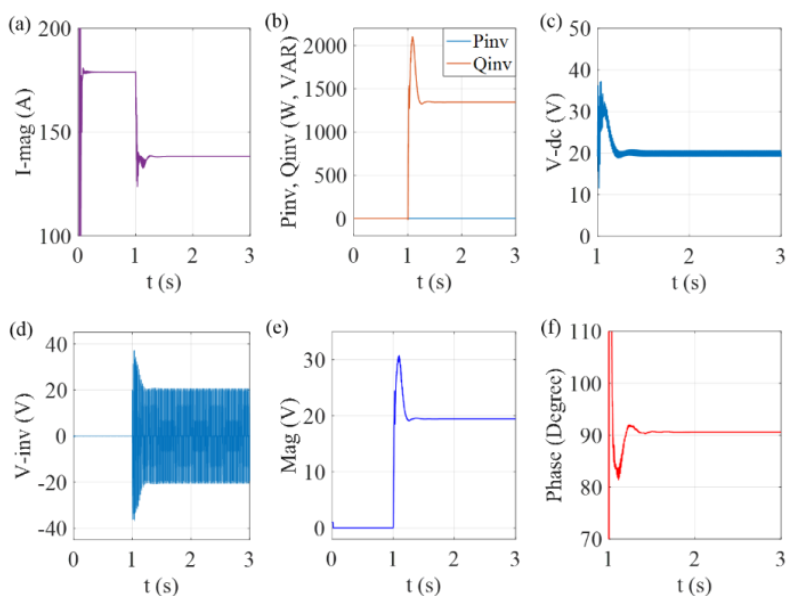

Figure 4. Performance of the H-bridge inverter in the inductive operation mode
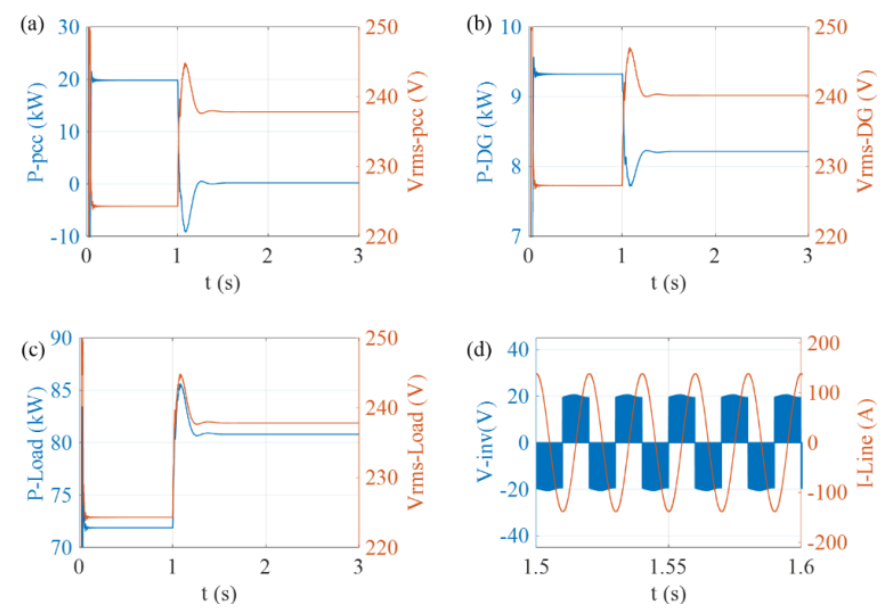

Figure 5. System performance before and after the H-bridge inductive operation.

\subsection{Case 2: $P_{P C C}<0$}

In this case, the H-bridge inverter behaves as a capacitive impedance to reduce the real power import at PCC from the main grid to the microgrid depending on the controlled line current value. Before $(\mathrm{t}<$ $1 \mathrm{~s}$ ), the H-bridge control unit is blocked and consequently, the injected voltage is disabled. After ( $\mathrm{t}>1 \mathrm{~s}$ ), 
the H-bridge control unit starts to operate and the injected voltage is enabled, respectively. The line current is controlled from 200 A to 145 A as depicted in Figure 6 (a). Figure 6 (b) depict the real and reactive power of the H-bridge inverter. The real power value is zero during the capacitive operation mode since the angle is $\left(-90^{\circ}\right)$ with respect to the line current. The reactive power generated from the H-bridge inverter is a result of injecting series capacitive voltage. The DC link voltage is regulated to its reference value $(20 \mathrm{~V})$ as depicted in Figure 6 (c). Figure 6 (d) demonstrates the injected peak to peak voltage which appears at the terminals of the H-bridge. Figure 6 (e)-(f) depict the H-bridge voltage magnitude and phase angle with respect to the line current. As demonstrated, the injected voltage magnitude of the H-bridge is approximately $17 \mathrm{~V}$. Also, the phase angle is $-90^{\circ}$ with respect to the line current. Figure 7 (a) show the RMS voltage (orange line) and real power (blue line) at PCC before and after the H-bridge operation. The RMS voltage at PCC is decreased as a result of injecting capacitive voltage into the line and the real power at PCC is controlled from $(-20 \mathrm{~kW})$ to zero as a consequence of the balance between the total generated power and the utility load demand. The RMS voltage and real power of every distributed generator are depicted in Figure 7 (b). After ( $t>1 \mathrm{~s}$ ), it is clearly shown that the RMS voltage of the DG is decreased to a value which satisfy the PCC voltage decrease. Also, the real power of every DG is increased at ( $\mathrm{t}>1 \mathrm{~s})$ approximately from $9.3 \mathrm{~kW}$ to $10.2 \mathrm{~kW}$ as their RMS voltages are decreased. This increase of the DGs real power is due to the $P / V$ droop characteristic between the generated real power and the RMS voltage of every DG unit. Moreover, as the real power of the utility load is proportional to the PCC voltage, the real power of the load is decreased from approximately $113 \mathrm{~kW}$ to $102 \mathrm{~kW}$ as shown in Figure 7 (c). Figure 7 (d) depict the injected voltage and the line current in the capacitive operation mode.
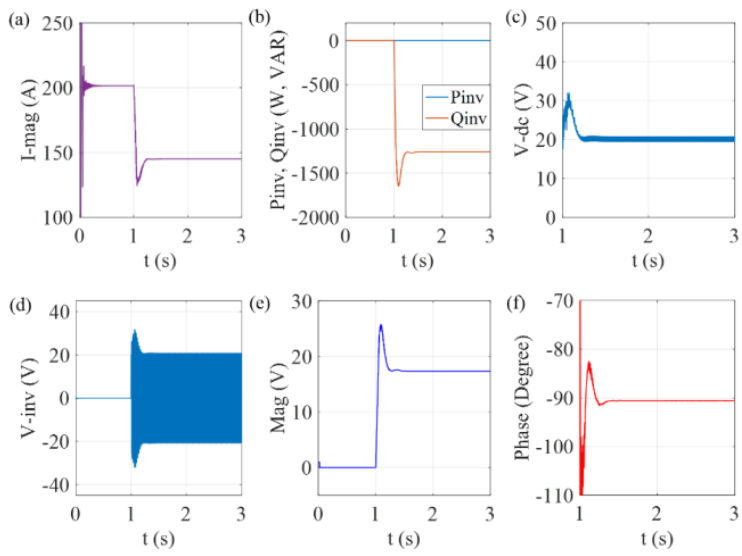

Figure 6. Performance of the H-bridge inverter in the capacitive operation mode
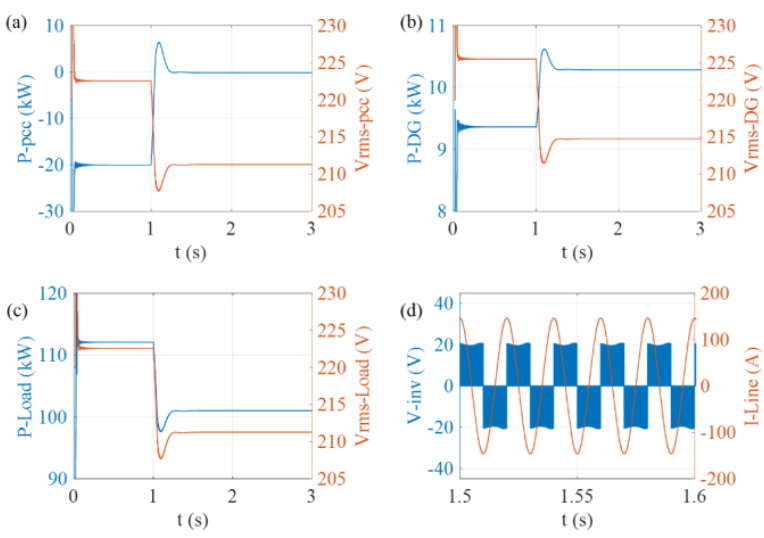

Figure 7. System performance before and after the H-bridge capacitive operation.

\subsection{THD of the PCC voltage}


In $400 \mathrm{~V}$ low-voltage distribution networks, the total harmonic distortion (THD) limit at PCC should not exceed 5\% as stated in [16]. Therefore, the PCC voltage has been testified regarding the harmonic spectrum during both cases either if the H-bridge inverter is operating in its inductive operation mode or its capacitive operation mode. Once the series converter starts to inject inductive or capacitive voltage at $(t>1 s)$, the first three cycles of the PCC voltage is taken to measure the THD as depicted in Figure 8 (a) and (b). It is clearly shown that the THD factor of the PCC voltage is small and below 5\% during both operation modes. In the inductive operation mode, the THD is about $1.79 \%$. However, in the capacitive mode, the THD is fairly $1.97 \%$.

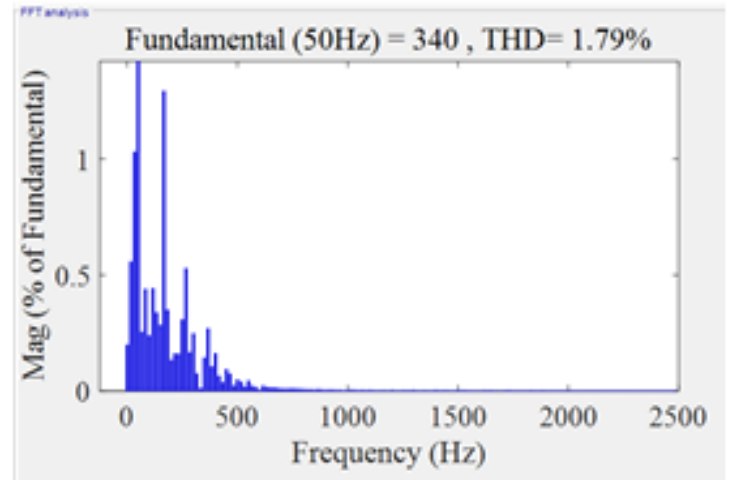

(a)

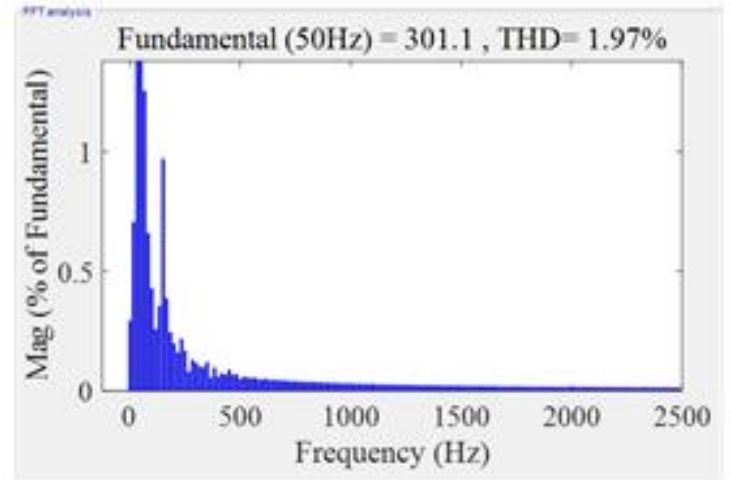

(b)

Figure 8: THD of PCC voltage during (a) inductive mode (b) capacitive mode

\section{CONCLUSION}

In this paper, an H-bridge inverter is located at PCC to control the real power transfer near to zero by controlling the line current. The line current control strategy has been designed in order to achieve this target. The simulation results show the effectiveness of the proposed control strategy in reducing the real power at PCC to zero during both inductive and capacitive operation modes. Besides, it was observed that the THD values of the PCC voltage in both operation modes are below the specified limit in low voltage distribution network..

\section{REFERENCES}

[1] B. K. Perera, P. Ciufo and S. Perera, "Point of common coupling (PCC) voltage control of a grid-connected solar photovoltaic (PV) system," in Industrial Electronics Society, IECON 2013 - 39th Annual Conference of the IEEE, Vienna, 2013.

[2] S. M. Amin, "Smart grid security, privacy, and resilient architectures: Opportunities and challenges," in Power and Energy Society General Meeting, IEEE, San Diego, 2012.

[3] J. M. Guerrero, J. C. Vasquez, J. Matas, L. G. Vicuna and M. Castilla, "Hierarchical control of droop-controlled AC and DC microgrids - A general approach toward standardization," IEEE Transactions on Industrial Electronics, vol. 58, no. 1, p. 158-172, 2011.

[4] A. Bidram and A. Davoudi, "Hierarchical structure of microgrids control system," IEEE Transactions on Smart Grid, vol. 3, no. 4, p. 1963-1976, 2012.

[5] B. Han, S. Baek and H. Kim, "Static synchronous series compensator based on cascaded H-bridge inverter," Electric Power Systems Research, vol. 65, no. 2, pp. 159-168, 2003.

[6] B. Pan, H. Yu, K. Li, Z. Zhao, Y. Jiang and L. Yuan, "A hierarchical control strategy for cascaded H-bridge multilevel static synchronous series compensator," in 2016 19th International Conference on Electrical Machines and Systems (ICEMS), Chiba, 2016.

[7] A. Pashaei, B. Zahawi and D. Giaouris, "New control method for distribution network distributed static series compensator," in 5th IET International Conference on Power Electronics, Machines and Drives (PEMD 2010), Brighton, 2010.

[8] M. Saradarzadeh, S. Farhangi, J. L. Schanen, P. O. Jeannin and D. Frey, "Application of cascaded H-bridge 
distribution-static synchronous series compensator in electrical distribution system power flow control," IET Power Electronics, vol. 5, no. 9, pp. 1660-1675, 2012.

[9] M. Saradarzadeh, S. Farhangi, J. L. Schanen and P. O. Jeannin, "A novel fuzzy logic DC bus voltage balancing controller for a D-SSSC cascaded H-bridge converter," in 2010 1st Power Electronic \& Drive Systems \& Technologies Conference (PEDSTC), Tehran, 2010.

[10] E. L.pelleter, s.bacha, r.caire and J.guiraud, "Active and reactive power flow control based on D-SSSC for looped and meshed distribution Grids," in 19th International Conference on Electricity Distribution, Vienna, 2007.

[11] K. D. Brabandere, B. Bolsens, J. V. d. Keybus, A. Woyte, J. Driesen and R. Belmans, "A voltage and frequency droop control method for parallel inverters," IEEE Transactions on Power Electronics, vol. 22, no. 4, pp. 1107-1115, 2007.

[12] Y. Xia, Y. Peng, P. Yang, M. Yu and W. Wei, "Distributed Coordination Control for Multiple Bidirectional Power Converters in a Hybrid AC/DC Microgrid," IEEE Transactions on Power Electronics, vol. 32, no. 6, pp. 4949-4959, 2017.

[13] Q. C. Zhong, "Robust Droop controller for accurate proportional load sharing among inverters operated in parallel," IEEE Transactions on Industrial Electronics, vol. 60, no. 4, pp. 1281-1290, 2013.

[14] J. He and Y. W. Li, "An enhanced microgrid load demand sharing strategy," IEEE Transactions on Power Electronics, vol. 27, no. 9, pp. 3984-3995, 2012.

[15] M. Monfared , M. Sanatkar and S. Golestan, "Direct active and reactive power control of single-phase grid-tie converters," IET Power Electronics, vol. 5, no. 8, p. 1544-1550, 2012.

[16] T. Hoevenaars, K. Colosino and M. LeDoux, "Interpreting IEEE STD 519 and meeting its harmonic limits in VFD applications," in IEEE Industry Applications Society 50th Annual Petroleum and Chemical Industry Conference, 2003.

\section{BIOGRAPHIES OF AUTHORS}

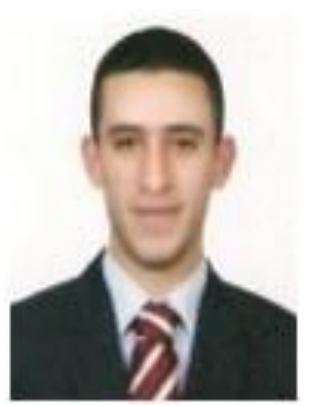

Qusay Salem was born in Irbid, Jordan. He receives the B.Sc. degree in electrical power engineering from University of Mutah in 2009, and the M.Sc. degree in electrical power engineering from Yarmouk University, Irbid, in 2012. He is currently working toward the Ph.D. degree in Electrical Energy Engineering at the Institute of Energy Conversion and Storage, University of Ulm, Ulm, Germany. His research interests include power control and power management in low-voltage smart microgrids, Islanding detection schemes, and series power flow controllers.

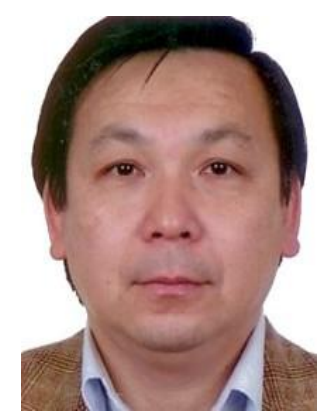

Jian Xie was born in Xiamen, China. He receives the B.Sc. degree in electrical engineering from Jiao-Tong University, Shanghai, in 1985, and the Diploma in electrical engineering from Technical University of Darmstadt, Darmstadt, in 1987, and the Ph.D. in electrical engineering from Technical University of Darmstadt, Darmstadt, in 1993. From 1988 to 1993, he was a Research Assistant with the Technical University of Darmstadt. From 1993 to 1998, he was a Development Engineer with AEG. Since 1998, he has been Full Professor with the Institute of Energy Conversion and Storage, University of Ulm, Ulm, Germany. From 2003 to 2010, he leads two projects at the University of Ulm. He has two registered patents. His research interests include advanced power converters, battery management systems, high frequency harmonics in railways, cascaded H-bridge inverters, smart grid and smart meters, decentralized control in microgrids. 